\title{
Investigation of the clinical functioning of the Dimensional Clinical Personality Inventory 2 criticism avoidance dimension
}

\author{
Investigação do funcionamento clínico da dimensão evitação a críticas do \\ Inventário Dimensional Clínico da Personalidade 2
}

Lucas de Francisco Carvalho, ${ }^{1}$ Catarina Possenti Sette,${ }^{1}$ Fabiano Koich Miguel ${ }^{2}$

\begin{abstract}
Objective: To investigate the clinical functioning of the criticism avoidance dimension from the Dimensional Clinical Personality Inventory 2 (Inventário Dimensional Clínico da Personalidade 2 [IDCP-2]), establishing a clinically relevant cut-off for the typical traits of avoidant personality disorder (AvPD) for screening purposes.

Methods: We administered the IDCP-2 to a sample of 2,276 subjects aged 18 to 90 years (mean $=26.95$, standard deviation=9.71). Of the total sample, 1,650 were women $(67 \%)$ and most were college students $(72.7 \%)$. The sample was divided into psychiatric patients diagnosed with other personality disorders (PDs) $(n=53)$, patients diagnosed with AvPD without comorbidities $(n=10)$, patients with AvPD with comorbidities $(n=42)$ and those without a known diagnosis of PD (nonpsychiatric patients; $n=2,171$ ).

Results: We checked for psychometric properties, assessed the adequacy of psychometric assumptions, and proceeded to focus analyses. The Wright item-person map showed the predominance of patients with AvPD in high levels of the scale. Analysis of variance (ANOVA) post hoc comparisons pointed to significant and expressive differences for almost all the comparisons; in the receiver operating characteristic (ROC) curve, we observed a sensitivity of $79 \%$ and a specificity of $87 \%$.

Conclusion: We found a suitable cut-off for the dimension, and results suggest that the dimension may help clinicians discriminate between patients with and without high levels in the symptoms of AvPD.
\end{abstract}

Keywords: Personality assessment, personality disorders, DSM; mental disorders.

\section{Resumo}

Objetivo: Investigar o funcionamento clínico da dimensão evitação a críticas do Inventário Dimensional Clínico da Personalidade 2 (IDCP-2), estabelecendo um ponto de corte relevante para traços típicos do transtorno da personalidade evitativa (avoidant personality disorder - AvPD), para finalidade de triagem.

Métodos: Nós aplicamos o IDCP-2 em uma amostra de 2.276 pessoas com idade entre 18 e 90 anos (média=26,95; desvio padrão $=9,71)$. Dessa amostra, 1.650 eram mulheres $(67 \%)$ e a maioria era de universitários ( $72,7 \%)$. A amostra foi dividida em pacientes psiquiátricos com outros transtornos de personalidade (PD; $n=53)$, pacientes com AvPD sem comorbidades $(n=10)$, pacientes com AvPD com comorbidades $(n=42)$ e aqueles sem diagnóstico conhecido de PD (pacientes não psiquiátricos; $\mathrm{n}=2.171$ ).

Resultados: Foram verificadas as propriedades psicométricas, investigando a adequação dos pressupostos psicométricos, e então procedemos às análises principais. O mapa Wright de itens-pessoas mostrou a predominância de pacientes com AvPD nos níveis mais altos da escala. Análises post hoc, pela análise de variância (ANOVA), apontou para diferenças significativas e expressivas para quase todas as comparações; na curva ROC, nós observamos sensibilidade de $79 \%$ e especificidade de $87 \%$. Conclusão: Foi encontrado um ponto de corte adequado para a dimensão, e os resultados sugerem que a dimensão pode auxiliar clínicos a discriminar pacientes com elevação nos traços do AvPD de pacientes sem elevação nesses traços.

Descritores: Avaliação da personalidade, transtornos da personalidade, DSM, transtornos mentais.

\footnotetext{
${ }^{1}$ Universidade São Francisco (USF), Campinas, SP, Brazil. 2 Universidade Estadual de Londrina (UEL), Londrina, PR, Brazil. Submitted Mar 30 2017, accepted for publication Aug 012017.

Suggested citation: Carvalho LF, Sette CP, Miguel FK. Investigation of the clinical functioning of the Dimensional Clinical Personality Inventory 2 criticism avoidance dimension. Trends Psychiatry Psychother. 2018;40(2):93-103. http://dx.doi.org/10.1590/2237-6089-2017-0038
} 


\section{Introduction}

Twelve epidemiological studies found that the average prevalence of avoidant personality disorder (AvPD) was $1.7 \%$, making it one of the most prevalent personality disorders (PD). ${ }^{1}$ Other studies have shown that the prevalence of AvPD ranges between 11 and $57 \%$ in clinical samples, ${ }^{2-4}$ and between 0.5 and $5 \%$ in the general population. ${ }^{5-6}$ Even though this prevalence is considered high, there are few studies focusing on AvPD; for example, Widiger ${ }^{7}$ shows the number of articles published on each PD, demonstrating that there is a significant amount of research in the area, but AvPD is the sixth least studied among the 10 disorders addressed.

AvPD is defined by the Diagnostic and Statistical Manual of Mental Disorders, 5th edition (DSM-5), ${ }^{8}$ section 2, as a persistent pattern of social inhibition and hypersensitivity to negative evaluation. This pattern includes low self-esteem and distrust features associated with excessive feelings of shame or inadequacy and avoidance of situations and activities involving interpersonal contact because of fear of criticism and/ or disapproval; patients are prone to sad or irritable mood, anxiety, anhedonia and mood oscillations. Individuals diagnosed with AvPD tend to have social withdrawal, despite the desire to establish close social relationships, causing a tendency to intensely attach to the few people with whom they relate. Because of that, these patients live in a constant state of ambivalence, which often causes significant psychological distress. The tendency to avoid social contact is through fear of feeling humiliated, related to the fear of being rejected, with shyness and elusiveness being used as defense mechanisms against embarrassing situations in which the individual is dominated by intense fear of rejection or failure. ${ }^{8}$

On the international panorama, it is possible to find several assessment tools with stimuli related to typical pathological features of AvPD (e.g., the Personality Inventory for DSM-5 [PID-5]). ${ }^{9}$ In Brazil, the Dimensional Clinical Personality Inventory 2 (Inventário Dimensional Clínico da Personalidade 2 [IDCP-2] $)^{10}$ figures as a single instrument developed in the country for the assessment of pathological personality traits related to various PDs. The IDCP-2 is a self-report instrument built based on diagnostic criteria set forth in the DSMIV-TR ${ }^{11}$ and on clinical practice focused on PDs. ${ }^{12-15}$ It has been shown to present adequate psychometric properties. ${ }^{16,17}$ It comprises 163 items divided into 12 dimensions: dependency, aggressiveness, mood instability, eccentricity, attention seeking, distrust, grandiosity, isolation, criticism avoidance, self-sacrifice, conscientiousness and impulsiveness. The dimension that is most strongly related to AvPD is criticism avoidance, ${ }^{18}$ assessing traits related to beliefs of inability and inadequacy, fear of humiliation, criticism and rejection, anxiety, social and intimacy avoidance.

A study conducted by Abela et al. ${ }^{18}$ compared the group profile of participants with AvPD without associated comorbidities $(n=10)$ with the profile of those with AvPD and associated comorbidities $(n=42)$ and also with other participants with a diagnosis of PD other than AvPD ( $n=35)$, using the IDCP. Among the findings, the group with AvPD and other comorbid PDs presented the highest score in the criticism avoidance dimension. The group with AvPD and comorbidities showed a more severe profile in all dimensions, with higher scores in the criticism avoidance dimension when compared to the group with AvPD and no comorbidities, and in almost all dimensions when compared to non-avoidant group. In addition, Carvalho \& Primi ${ }^{16}$ conducted a study with 94 subjects without a diagnosis of PD, using the IDCP and the Revised NEO Personality Inventory (NEO-PI-R) - the latter was used as an indicator of PDs through prototype matching procedure. Among the data collected, there was a significant relationship between the criticism avoidance dimension and AvPD ( $r=0.62)$.

In order to review the IDCP criticism avoidance dimension according to Carvalho \& Primi ${ }^{16}$ and to assess its psychometric properties, Carvalho \& Sette ${ }^{19}$ conducted a study adopting a procedure divided in two stages. The first stage was the development of new items for the dimension, while the second stage proceeded to empirical research with data collection, in order to investigate the internal structure, reliability coefficients for internal consistency and relations with external variables of the revised dimension. In the data collected for the second stage, seven original items and 39 new items were used. After psychometric analysis, the revised dimension consisted of 18 items, including two original and 16 new items, divided into three factors, named as anxious preoccupation (concerns about the possibility of unpleasant events happening and concerns with the future), generalized avoidance (characteristics such as sense of embarrassment when speaking in public and being in social situations, difficulty establishing interpersonal relationships, and fear of being the focus of attention) and intimate relations avoidance (difficulty getting emotionally involved, little interest in intimate friendships). In addition to the three factors, the revised scale also had a total score. Regarding the internal consistency of the factors found, all had coefficients $>0.80$, and the dimension with the total set of items had a coefficient of 0.87 . Correlations of the IDCP dimension and its factors with the NEO-PI-R 
ranged from 0.15 to 0.56 with the facets of neuroticism, and from -0.14 to 0.35 with the facets of extroversion; all correlations were statistically significant with the PID-5 (anxiety, $r=0.70$; depression, $r=0.69$; intimacy avoidance, $r=0.44$; withdrawal, $r=0.65$ ).

However, there are no studies establishing a clinical cut-off that could potentially suggest which scores are clinically relevant for the diagnosis of AvPD. In order to advance the studies with the criticism avoidance dimension, the present research aims to investigate the clinical functioning of this IDCP dimension, establishing a clinically relevant cut-off for typical features of AvPD, for screening purposes. Based on that goal, three hypotheses were developed: H1 - items should more accurately assess the most pathological levels of the latent construct; $\mathrm{H} 2$ - individuals should be located in the more upper levels of the latent construct the more pathological personality features related to the diagnosis of AvPD they present; H3 - the total dimension will discriminate groups according to the pathology level of AvPD characteristics.

\section{Method}

\section{Participants}

This study comprised 2,276 participants, aged 18 to 90 years $($ mean $=26.95$, standard deviation $[S D]=9.71)$. Of the total sample, 1,650 were women (76\%) and most were college students $(72.7 \%)$, selected by convenience sampling. Subsequently, the sample was divided into four groups, according to external criteria: psychiatric patients diagnosed with other PDs $(n=53)$, patients diagnosed with AvPD without comorbidities $(n=10)$, patients with AvPD with comorbidities $(n=42)$, totalizing 105 patients with a known psychiatric diagnosis, and those without a known diagnosis of PD (non-psychiatric patients; $n=2,171$ ). Participants of the first three groups were recruited at a public psychiatric hospital and the fourth group at private universities. All institutions were located in the state of São Paulo. Psychiatric patients were diagnosed by psychiatrists with at least five years of experience using the Structured Clinical Interview for DSM Axis I and Axis II (SCID-I and SCID-II). The fourth group (non-psychiatric), were selected from the general population and did not have a known psychiatric diagnosis; however, a psychiatric evaluation of these participants was not performed. Table 1 presents the demographic characteristics of the groups, i.e., gender, age, educational level, psychiatric treatment, use of psychotropic medications, and psychotherapy treatment.

\section{Instruments}

The IDCP-2 is a revised version of the IDCP ${ }^{10}$ that covers the pathological characteristics described in Millon's theoretical proposal, ${ }^{20}$ the diagnostic categories of the DSM-IV-TR Axis II ${ }^{11}$ and section 2 of the DSM5,8 as well as the traits reported in section 3 of the DSM- 5 and in the PID $-5,{ }^{9}$ the dimensions assessed by the Shedler-Westen Assessment Procedure (SWAP), ${ }^{21}$ and the dimensions listed by Clark, ${ }^{22}$ which provide the basis for the Schedule for Nonadaptive Personality (SNAP). The IDCP-2 is a self-report instrument designed to assess pathological personality traits, comprising 206 items distributed in 12 dimensions (dependency, aggressiveness, mood instability, eccentricity, attention seeking, distrust, grandiosity, isolation, criticism avoidance, self-sacrifice, conscientiousness, and impulsiveness). Items must be answered using a Likert scale of four points, ranging from "it has nothing to do with me" (1) to "it has a lot to do with me" (4). Psychometric properties of the dimensions, evidence of validity (based on the internal structure and external variables) and reliability indices (for internal consistency) have been shown to be appropriate in

Table 1 - Demographic data according to group

\begin{tabular}{|c|c|c|c|c|c|c|c|}
\hline & \multicolumn{2}{|c|}{ Gender } & \multirow{2}{*}{$\begin{array}{c}\text { Age } \\
\text { Mean (SD) }\end{array}$} & \multirow{2}{*}{$\begin{array}{c}\text { Educational level } \\
\%\end{array}$} & \multirow{2}{*}{$\begin{array}{c}\text { Psy1 } \\
\text { n }\end{array}$} & \multirow{2}{*}{$\begin{array}{c}\text { Psy2 } \\
\text { n }\end{array}$} & \multirow{2}{*}{$\begin{array}{c}\text { Psy3 } \\
\text { n }\end{array}$} \\
\hline & M & $\mathbf{F}$ & & & & & \\
\hline $\begin{array}{l}\text { Avoidant PD without } \\
\text { comorbidities }\end{array}$ & 9 & 1 & $43.11(13.87)$ & $40 \%$ completed high school & - & - & - \\
\hline Avoidant PD with comorbidities & 31 & 11 & $39.50(13.49)$ & $50 \%$ completed high school & - & - & - \\
\hline Psychiatric patients & 42 & 11 & $40.58(11.67)$ & $37.7 \%$ incomplete college & - & - & - \\
\hline Non-psychiatric patients & 1,471 & 700 & $25.47(7.98)$ & $80 \%$ incomplete college & 104 & 57 & 337 \\
\hline
\end{tabular}

$\mathrm{F}=$ female; $\mathrm{M}=$ male; $\mathrm{PD}=$ personality disorder; Psy1 = psychiatric treatment; Psy 2 = use of psychotropic medications; Psy 3 = psychotherapy treatment; $\mathrm{SD}=$ standard deviation.

All patients were receiving psychological and psychiatric treatment (including use of psychotropic medication). 
studies that provide a basis for the IDCP-2. ${ }^{19,23-27}$ For the present study, we used the revised version of the criticism avoidance dimension, ${ }^{19}$ which contains 18 items divided into three factors: anxious preoccupation (4 items), generalized avoidance (10 items), and intimate relations avoidance (4 items). They all form a total score. We also used the original dimension, ${ }^{10}$ consisting of seven items, as a mean to perform the equating procedure, as related in the next topic.

\section{Procedures}

Oncethestudy protocol wassubmitted to and approved by the research ethics committee of Universidade São Francisco (CAAE 21992113.1.0000.5514), data collection was initiated. The instrument was administered at a private university in the state of São Paulo and at a public psychiatric hospital in the city of São Paulo. At the university, administration was conducted collectively, lasting about 30 minutes in one session per class, in the classrooms. After explaining the research goals, the participants signed an informed consent form and then completed the instrument.

Considering that 2,250 individuals answered only the original criticism avoidance dimension items and 214 (from the non-psychiatric group) answered both instruments (i.e., both the original and the revised items), we employed an equating procedure ${ }^{28}$ using all the 214 subjects as anchor. This subsample, in addition to answering all items of the original and revised versions of the dimension, answered another 23 items contained in the revised dimension ${ }^{19}$ but were not retained in the final version. We chose to use these items for equating purposes in order to provide more information to the statistical software. It should be noted that two items were common to both the original and the revised versions of the dimension, which also served as anchor in the equating procedure.

Data were analyzed using the rating scale model. ${ }^{29}$ The distinctive feature of this model is that the scalar intervals between points are deemed relatively similar for all items. The difficulty parameter $b_{i}$ represents the location of item $i$, or the average intensity of the thresholds of an item. Items that represent extremes in the latent dimension are represented with high average thresholds because their thresholds are all located on the most intense trait levels. Item and subject model parameters were calibrated using the joint maximum likelihood estimation method, implemented in the Winsteps software. ${ }^{30}$ This calibration was performed considering original and revised items, so that the parameters would be estimated considering all participants, which is the purpose of the equating procedure.
The fit of the calibration was assessed by the indices fit, infit and outfit, which were calculated for all the items and participants. These values are directly proportional to the residuals, reflecting differences between the observed and expected responses from the hypothesized knowledge of the model parameters, thus providing evidence of how well the model fits the data. Values $>1.3$ indicate misfit. ${ }^{31}$ Complementarily, we calculated the item-theta correlation, the general reliability ( $a$ and Rasch) and the local reliability. ${ }^{32}$

After that, considering the scope of the study, we generated the Wright map, item map, group comparisons (analysis of variance [ANOVA]) and receiver operating characteristic [ROC] curve, aiming to achieve a better understanding of the latent construct and also to establish cut-offs for the dimensions. In terms of ROC curve application, the psychiatric sample accounted for approximately $5 \%$ of the total sample of this study, which is in line with the prevalence for PDs in the general population. In addition, the sample of patients with AvPD represented $2.4 \%$ of the total sample of this study, which agrees with what is expected in terms of prevalence. ${ }^{8}$ Qualitative item map analyses were based on the recommendations of Elliot et al. ${ }^{33}$

\section{Results}

At first, in line with the purpose of this study, we analyzed psychometric assumptions. Data were analyzed mainly at the level of the criticism avoidance dimension items, but we also considered the total score and the three factors previously found from the revised version of this dimension. ${ }^{19}$

We tested the possibility of unidimensionality in order to guarantee the assumptions of the mathematical model underlying the equating procedure (i.e., Rasch model). To check the unidimensionality, principal component residual analysis was used, based on the inferiority criterion, i.e., residuals were considered when reaching eigenvalues $\geq 2.0 .^{34}$ There was a first residual with an eigenvalue of $2.8(8.9 \% ; 15.7 \%$ of explained variance). However, Linacre ${ }^{34}$ suggests the use of latent correlation (error-disattenuated) in such cases; from the $\mathrm{C} / \mathrm{sqrt}(\mathrm{R} 1 * \mathrm{R} 2)$ formula, we found a coefficient of 0.57 . The results indicate sufficient relationship to consider the unidimensionality of the scale, and therefore the analyses with the total group of items were maintained.

We also investigated the functioning of response categories that had at least one range in theta in which each category was the most likely response, indicating suitability of the Likert scale employed. Furthermore, 
as expected, an increasing order could be observed between the categories $(1<2<3<4)$, also consistent with the scale used. Because the assumptions of unidimensionality and the proper functioning of response categories were confirmed, item parameters were estimated by investigating their psychometric adequacy.

Table 2 shows the number of items, difficulty level for endorsement $(b)$, standard error, adjustment ratios (infit and outfit) and the theta-item correlation. Also, the table presents internal consistency reliability indices (based on the Rasch model and Cronbach's alpha).

As shown in Table 2, some items had positive $b$ values, while other had negative values. These values should be considered observing the mean theta and SD of the sample (mean=-0.91, $S D=1.13$ ), as items with $b$ values higher than the mean theta tend to be most agreed with (this is even more true for those outside the SD range), and the opposite is also true, i.e., items with $b$ values lower than the mean theta tend to be disagreed. For example, the most extreme item in the latent construct (i.e., less endorsed) was $488(b=0.70)$, and the most endorsed one was item $468(b=-1.65)$. As for infit and outfit indices, considering the criterion proposed by Wright \& Linacre ${ }^{31}$ (i.e., $\leq 1.3$ being regarded as appropriate), only one item (468) showed a discrepancy in the mathematical model, even though the values found (1.44 for infit and 1.51 for outfit) were marginally similar to the established criteria, not requiring the deletion of the item. Another reason behind our decision not to exclude that item was its item-theta correlation of moderate magnitude $(r=0.54)$ and its relevance in terms of construct coverage as assessed in a previous study. ${ }^{19}$ In addition, regarding the correlations between the items and theta values, all items showed moderate to high correlations with the total score, suggesting that all items tend to contribute to evaluate the latent construct.

Concerning the reliability of the set of items, it is possible to observe a clear discrepancy between the reliability calculated using the Rasch model vs. Cronbach's alpha values - the latter yielding significantly higher results. It is likely that, given the location of the difference between latent construct items and people, the reliability calculation of the Rasch model presents losses. Thus, we evaluated the test's information curve, identifying reliability indices according to the metric of the latent construct (Figure 1).

Table 2 - Descriptive statistics for the items included in the criticism avoidance dimension of the Dimensional Clinical Personality Inventory 2 (Inventário Dimensional Clínico da Personalidade 2 [IDCP-2])

\begin{tabular}{|c|c|c|c|c|c|}
\hline Item & Measure (b) & SE & Infit & Outfit & $\boldsymbol{r}_{\text {item-theta }}$ \\
\hline 488 & 0.70 & 0.06 & 1.09 & 1.00 & 0.40 \\
\hline 34 & 0.68 & 0.04 & 0.87 & 0.81 & 0.69 \\
\hline 487 & 0.54 & 0.06 & 1.09 & 1.00 & 0.41 \\
\hline 499 & 0.34 & 0.06 & 0.81 & 0.64 & 0.54 \\
\hline 83 & 0.29 & 0.04 & 1.01 & 1.07 & 0.70 \\
\hline 503 & 0.27 & 0.06 & 0.95 & 1.02 & 0.48 \\
\hline 489 & 0.26 & 0.06 & 1.10 & 1.06 & 0.44 \\
\hline 483 & 0.23 & 0.06 & 0.91 & 0.78 & 0.52 \\
\hline 481 & 0.22 & 0.06 & 0.91 & 0.82 & 0.52 \\
\hline 486 & 0.20 & 0.05 & 1.09 & 1.10 & 0.45 \\
\hline 477 & 0.17 & 0.06 & 0.90 & 0.85 & 0.53 \\
\hline 466 & 0.14 & 0.05 & 0.88 & 0.88 & 0.52 \\
\hline 496 & -0.29 & 0.05 & 0.79 & 0.77 & 0.64 \\
\hline 469 & -0.60 & 0.05 & 0.91 & 0.85 & 0.63 \\
\hline 471 & -0.77 & 0.05 & 1.03 & 0.99 & 0.61 \\
\hline 494 & -0.83 & 0.05 & 1.21 & 1.26 & 0.53 \\
\hline 470 & -0.85 & 0.05 & 1.17 & 1.13 & 0.57 \\
\hline 468 & -1.65 & 0.04 & 1.44 & 1.51 & 0.54 \\
\hline$b$, mean (SD) & & & $0.00(0.62)$ & & \\
\hline Infit, mean (SD) & & & $1.01(0.16)$ & & \\
\hline Outfit, mean (SD) & & & $0.97(0.20)$ & & \\
\hline Rasch reliability (a) & & & $0.59(0.88)$ & & \\
\hline
\end{tabular}

$\mathrm{SD}=$ standard deviation; SE = standard error. 
According to Figure 1 , the criticism avoidance dimension was more accurate (i.e., equal to 0.92) around the zero point in the latent construct, between -0.5 and +0.5 . This range is the mean obtained by the groups diagnosed with AvPD (with and without comorbidities).

Given the adequacy of psychometric assumptions (unidimensionality, response categories and reliability indices) and the estimation of item and person parameters, we proceeded with focus analyses. Figure 2 (Wright item-person map) shows the relationship between items and participants in a common metric scale representing the latent construct (i.e., avoidance functioning). On the right side of the figure, numbers are used to designate the participants in each group of this study: 1 - non-patients (not greyed); 2 - psychiatric patients without a diagnosis of AvPD (light greyed); 3 - patients diagnosed with AvPD with no comorbidities (dark greyed); 4 - patients diagnosed with AvPD with comorbidities (dark greyed). To the left, numbers indicate the items on the criticism avoidance dimension of the IDCP.

The majority $(\sim 70 \%)$ of the patients (i.e., numbers 2, 3 and 4) are located at the top of the continuum, i.e., above the mean, demonstrating that the patient groups tend to endorse most items. The group of non-patients (i.e., number 1 ) was the most representative in the lower portion of the map (i.e., below the mean of the latent variable). However, we observed that the bottom line of the map consisted primarily of patients, with 21 psychiatric patients (non-AvPD; identified by number 2 ) and 11 patients with AvPD diagnosis (numbers 3 and 4),

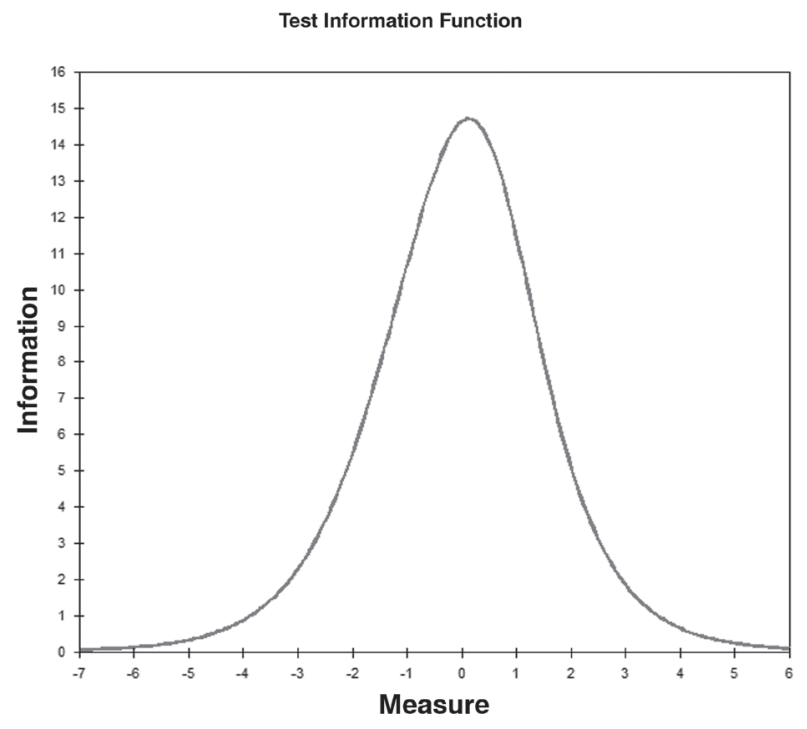

Figure 1 - Test information curve whether or not they had comorbidities. Complementary to these data, we performed ANOVA using only the sample included in the analysis in Figure 2, observing the ability of the criticism avoidance dimension to discriminate the groups according to severity of avoidant functioning, which can help establish a cut-off for this dimension of the IDCP, along with the other data presented. Table 3 shows the results of ANOVA post hoc comparisons for the four groups and Cohen's $d$ for peerto-peer comparisons.

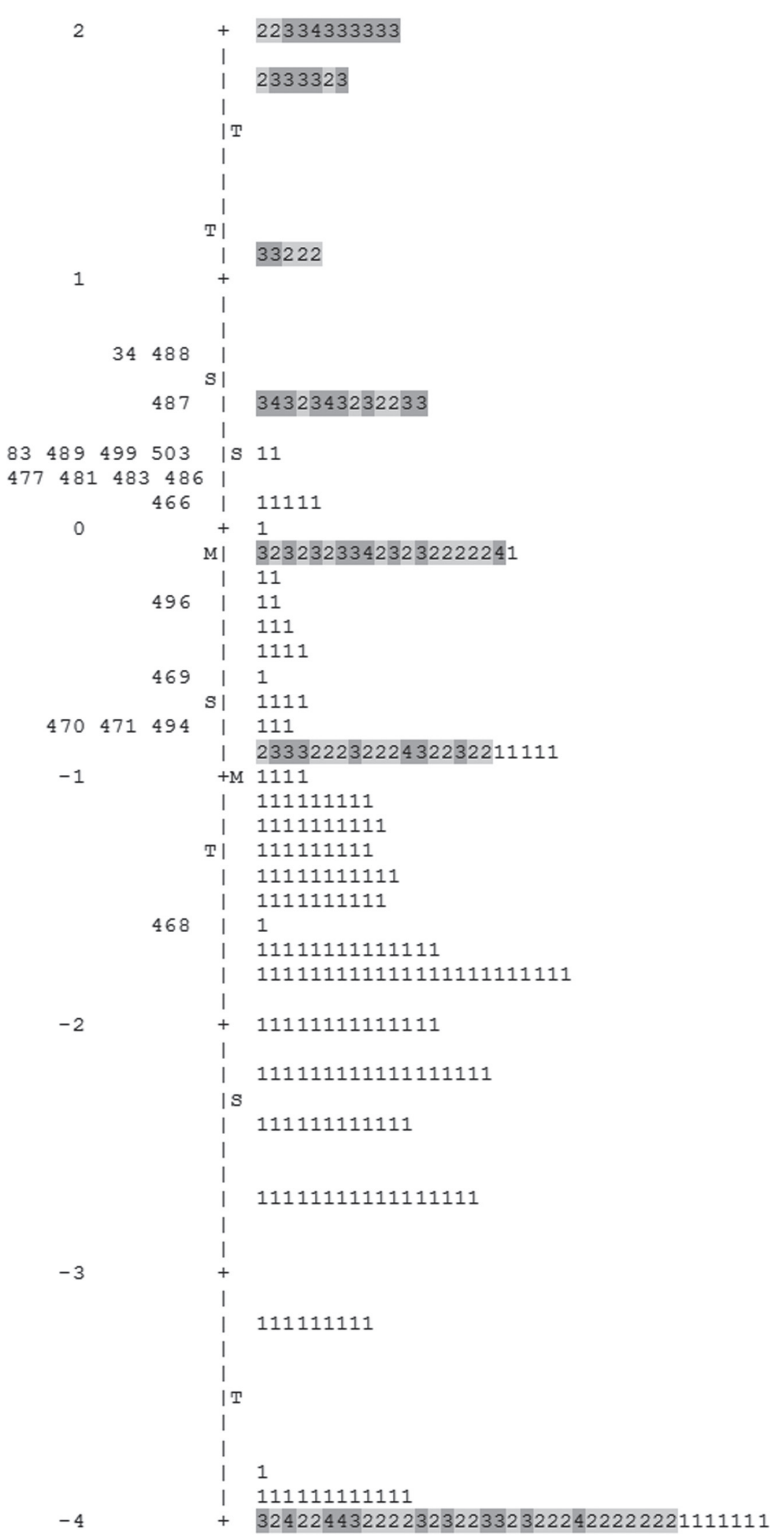

Figure $\mathbf{2}$ - Wright item-person map of the criticism avoidance dimension 
According to Table 3 and corroborating what was noted earlier in the map, the lowest means were obtained by non-psychiatric participants, and the highest ones by avoidant patients without comorbidity, followed by patients with comorbidities. Still, the groups were reorganized into three: the first one comprising only non-patients, the second including psychiatric patients without a diagnosis of AvPD diagnosis and without comorbidities, and the last one comprising patients with a diagnosis of AvPD with comorbidities. It is also remarkable that the magnitudes of the differences were more significant between the group of non-patients vs. the group with AvPD and comorbidities, than between the group of non-patients vss the group with AvPD and no comorbidities. The only comparison that failed to show significant results was that between the group of psychiatric patients without AvPD (non-AvPD) and AvPD without comorbidities. We also tested the impact of some demographic variables (i.e., gender, age, and educational level), but none of these variables were significant $(p>0.05)$ and the effect in the comparison remained significant.

A final analysis conducted to establish an optimal cut-off for screening purposes was the ROC curve. The area under the curve (AUC) was equal to 0.84 ( $95 \%$ confidence interval $[95 \% \mathrm{CI}] 0.76-0.91)$ and the raw to theta score that seemed to have the best sensitivity/ specificity was -0.89 , with sensitivity of $79 \%$ and specificity of $87 \%$. Considering the cut-off in theta of -0.89 , the corresponding raw score was 33 points.

To illustrate possible practical applications of these data, Figure 3 presents the item map, with the items

Table 3 - ANOVA post hoc comparison between the groups

\begin{tabular}{|c|c|c|c|c|}
\hline \multirow[b]{2}{*}{ Group } & \multicolumn{3}{|c|}{ Mean (SD) } & \multirow[b]{2}{*}{$\boldsymbol{d}$} \\
\hline & 1 & 2 & 3 & \\
\hline Non-patient $(n=215)$ & $-1.90(1.08)$ & & & dnon-patient*nonAvPD $=1.00$ \\
\hline Non-AvPD $(n=53)$ & & $-0.75(1.40)$ & & dnon-patient*AvPD=1.22 \\
\hline AvPD without comorbidities $(n=10)$ & & $-0.54(1.70)$ & & $\begin{array}{c}\text { dnon-patient*AvPDcom }=1.94 \\
\text { dnon-AvPD*AvPD }=0.14\end{array}$ \\
\hline AvPD with comorbidities $(n=42)$ & & & $0.44(1.71)$ & dnon-AvPD*AvPDcom $=0.77$ \\
\hline $\mathrm{p}$ & 1.00 & 0.93 & 1.00 & $\mathrm{dAvPD} * A v P D \operatorname{com}=0.57$ \\
\hline
\end{tabular}

ANOVA = analysis of variance; AVPD = avoidant personality disorder; com = comorbidities; SD = standard deviation. $d \geq 0.20$ was considered as expressive.



Figure 3 - Item map for the criticism avoidance dimension (items and total scores) 
located on the right side (from bottom to top, most to least endorsed item) and the theta scale in the bottom part of the figure. The central part, starting at the bottom and reaching the top of the figure, shows the response categories for each of the items.

Participants gathered between the values -3 and +1 in the theta range. Based on a cut-off of -0.89 (i.e., raw score of 33 points), a vertical line was drawn, illustrating a hypothetical patient reaching the established cut-off score. As a result, it was possible to see the pattern of responses expected for the hypothetical patient, i.e., tendency to agree (categories 3 and 4 ) with the first item (468), with an approximate $50 \%$ probability to agree with the following three items (470, 494, and 471 ), and a low probability to agree with the other items (i.e., more likely to answer 1 or 2 in the other items). We observed a clear tendency, for a patient reaching the threshold of the cut-off, to agree with a small number of items compared to the total number of items in the dimension.

\section{Discussion}

The aim of this study was to investigate the clinical functioning of the criticism avoidance dimension, as well as to establish a clinically relevant cut-off for the typical features of AvPD, for screening purposes. The results demonstrated the possibility of using this scale for assessing pathological personality features related to AvPD. Accordingly, this study may contribute to increase the availability of valid instruments to assess PD in the Brazilian context (in this case, specifically AvPD). Considering the use of the dimension and cut-off here established, it is possible to map the presence of the characteristics that may be relevant as early indicators of the presence of a diagnosis of AvPD in some patients, thereby assisting in decision-making in clinical practice.

To achieve the objective proposed in this study, initially we investigated psychometric assumptions, and the results demonstrated the appropriateness of the set of items, indicating that the conditions were met (i.e., unidimensionality, response categories, parameter estimation, and reliability). Subsequently, another analysis was conducted considering the scope of the study. In the next paragraphs, the data found will be discussed in detail in the light of the hypotheses previously raised. We emphasize that the reliability indices also helped to check which range of the latent construct (i.e., avoidant functioning) was more appropriate. This will also be discussed in detail below.

Regarding the calculation of the reliability index of the item set, the results obtained with the rating scale model (0.59) and with Cronbach's alpha values (0.88) showed discrepancy, possibly because of different methods employed to calculate each coefficient (in the first case, scale ranges with respondents and no items affect the reliability calculation more directly). Going deeper in the analysis of these data, we also calculated the test information curve, ${ }^{35}$ which suggested that individuals located between -0.5 and 0.5 on the graph are evaluated by the dimension with more information (more accurately), i.e., with fewer errors and therefore a higher level of reliability. ${ }^{34}$ The means obtained by the AvPD patients without comorbidities and with comorbidities were within the more accurate range of the instrument, which was not observed with the means obtained by the general population. This fact suggests a good functioning of the dimension investigated, indicating a low level of error in evaluating the desired range (i.e., pathological), and confirming the first hypothesis $(\mathrm{H} 1)$ of this study.

With regard to the items of the scale, as seen in Table 2 and Figure 2, item 468 ("I know I'm very anxious" - anxious preoccupation factor) was the most endorsed one by the sample, and this is the only item with a $100 \%$ chance to be agreed with when the individual reaches the cut-off established in this study. This was also the only item in the dimension which showed discrepancy in the mathematical model, with rates marginally above the established criteria. ${ }^{31}$ Nevertheless, we suggest keeping the item because it presents moderate itemtheta correlation and covers new content previously not contemplated by the criticism avoidance dimension. ${ }^{19}$ The content of this item is related to generalized, persistent anxiety, rather than associated with specific situations that trigger anxiety. On the one hand, generalized anxiety is an AvPD component ${ }^{8}$; on the other hand, the fact that it is more global may explain why it is among the most endorsed ones. In turn, the least endorsed item was 488 ("I would rather be alone, without a loving partner" - intimacy avoidance factor), typically more related to features present in the diagnosis of AvPD, such as social inhibition and avoidance of situations and activities involving interpersonal contact. ${ }^{8}$ Interestingly, this item refers to one of the broad areas understood as detrimental in people with PDs, namely, interpersonal relationships. ${ }^{36}$ These data suggest that the characteristic measured by item 488 is less typical in the population when related to item 468 .

Considering the location of the items in the latent construct in relation to the participants, the results presented in Figure 2 indicate that most patients are located at the top of the continuum, tending to endorse more items. However, we observed that the last line of the map comprised patients, with 21 psychiatric (non-AvPD) 
and 11 AvPD patients with and without comorbidities. Perhaps what explains the presence of these patients are AvPD comorbidities, with the most frequent PDs being not otherwise specified (NOS), borderline, paranoid, and histrionic. It should be noted that avoidant functioning is not typical in patients with these diagnoses. ${ }^{8}$ These data partially confirmed $\mathrm{H} 2$, as we observed a tendency to item endorsement by people known to have more typical features of AvPD. Both AvPD and the criticism avoidance dimension are characterized by a tendency to display concern for the future, embarrassment in social situations and difficulty establishing social relationships or emotional involvement. ${ }^{16,18,19}$

Complementary to these data, based on the ANOVA, we found that the dimension was able to differentiate between non-patients vs. patients, and between patients with AvPD with vs. without comorbidities. Both the mean and magnitudes expressed in Cohen's $d$ suggest a clear distinction between most of the peer-to-peer comparisons between the groups. However, it was not possible to distinguish between non-AvPD patients and AvPD patients without comorbidities. This indicates that although the number of items is able to discriminate the various subgroups, such differentiation may be impaired when comparing patients with a specific diagnosis of AvPD vs. patients with other PDs. One of the factors that may explain this effect, which was not controlled in this study, is the presence of clinical disorders (Axis I) in the patients. For example, some of the patients in non-AvPD group may have social phobia or other anxiety disorders, which may explain the findings. Future studies should seek to determine whether these data can be replicated and then control for the diagnosis of clinical disorders. Problems in the criticism avoidance dimension of the IDCP could also explain the findings. However, previous studies have shown that both the original ${ }^{16,18}$ and the revised version ${ }^{19}$ of the dimension evaluate symptoms typically related to AvPD. These data partially confirm H3, since generally the items were able to discriminate the groups.

The data here presented suggest the possibility of establishing cut-offs for the criticism avoidance dimension. Specifically, we used the ROC curve to determine a cut-off that is clinically relevant for screening purposes. The results showed that the optimal cut-off was -0.89 , theta equivalent to the raw score of 33 points, with adequate specificity and sensitivity results, which is satisfactory, ${ }^{37}$ especially considering the context of psychiatric disorders. ${ }^{38-40}$ As shown in the item map (Figure 2), more than $70 \%$ of the psychiatric patients had theta values above 0.00 , suggesting that this cut-off is able to identify the majority of the patients included in this sample, as also noted earlier in the more precise ranges of the dimensions (i.e., between -0.5 and 0.5 ). It should be noted that, although these are appropriate values, screening instruments are expected to present higher levels of sensitivity than specificity, which was not the case in this study. Therefore, we suggest that all items be applied in patients with AvPD, to investigate other possible cut-off or to confirm our results. This could lead the dimension to be reviewed again or, at least, alert the professional to be careful during the screening process.

Considering the practical application of the criticism avoidance dimension by professionals, we presented Figure 3, which depicts a map that can be used in the clinical setting, providing a greater understanding of the pathological functioning of the patient, including the item level. ${ }^{33,40}$ Based on the cut-off here established, we observed that the hypothetical patient who achieved such score (raw score of 33 points) tends to agree with the first item (468). In the following items (470, 494 and 471 ) the probability of agreement is approximately $50 \%$. Items 470 and 471 refer to specific concerns depicting the vision of others in relation to the individual (being seen as concerned) and to the patient's concern regarding bad events that may occur in the future. Even though these items do not directly portray typical traits of AvPD, ${ }^{8}$ global anxiety is present in these patients. ${ }^{20}$ In turn, item 494 refers to the weight given by the subject to the criticism of others, i.e., seeing it as something terrible. This feature is present among the diagnostic criteria of the DSM $-5,{ }^{8}$ described as fear of criticism and/ or disapproval and fear of feeling humiliated, related to the fear of being rejected. ${ }^{8}$ Thus, it is possible to identify which characteristics will probably be observed by the clinician in patients with a tendency to present avoidant functioning. We emphasize that it is not necessary that the patient agree to all or most of the items to raise a hypothesis of avoidant traits; secondly, the clinician must remember that the use of the criticism avoidance dimension alone does not allow to establish a diagnosis, but can act as an important initial indicator in the assessment.

Limitations of this study should be considered, especially because this is a first exploratory step in the clinical application of the criticism avoidance dimension. The first limitation is the small number of psychiatric patients, mainly because patients with AvPD without comorbidities and non-patients did not undergo a clinical evaluation a priori, thus the presence of any other PD is unknown. One should also emphasize the equating procedure performed to ensure comparability of the entire sample. Despite being adopted in several studies, it may lead to bias when compared to analysis performed with a full database. Therefore, it is 
important that this research be replicated with all the items administered to all subjects. Additional limitations include the absence of control of certain variables, such as use of medication and presence of other axis I diagnoses, and the fact that participants were divided according to PD, which may have skewed the results. It is important that future studies seek to increase the representativeness of the sample of patients with AvPD without comorbidities, consider other diagnoses, and perform analyses such as differential functioning of the instrument, considering the sex of the participants.

\section{Acknowledgements}

This study received financial support from Fundação de Amparo à Pesquisa do Estado de São Paulo (FAPESP), Conselho Nacional de Desenvolvimento Científico e Tecnológico (CNPq), and Coordenação de Aperfeiçoamento de Pessoal de Nível Superior (CAPES).

\section{Disclosure}

No conflicts of interest declared concerning the publication of this article.

\section{References}

1. Torgersen S. Prevalence, sociodemographics, and functional impairment. In: Oldham JM, Skodol AE, Bender, DS, editors. Essentials of personality disorders. Washington: American Psychiatric Publishing; 2009. p. 83-102.

2. Stuart S, Pfohl B, Battaglia M, Bellodi L, Grove W, Cadoret R. The co-occurrence of DSM-III-R personality disorders. J Pers Disord. 1998; $12: 302-15$.

3. McGlashan TH, Grilo CM, Skodol AE, Gunderson JG, Shea MT, Morey LC, et al. The Collaborative Longitudinal Personality Disorders Study: baseline Axis I/II and II/II diagnostic cooccurrence. Acta Psychiatr Scand. 2000;102:256-64.

4. Zimmerman M, Rothchild L, Chelminski I. The prevalence of DSM-IV personality disorders in psychiatric outpatients. Am J Psychiatry. 2005;162:1911-8.

5. Hummelen B, Wilberg T, Pedersen G, Karterud S. An investigation of the validity of the Diagnostic and Statistical Manual of Mental Disorders, Fourth Edition avoidant personality disorder construct as a prototype category and the psychometric properties of the diagnostic criteria. Compr Psychiatry. 2006;47:376-83.

6. Torgersen $S$, Kringlen $E$, Cramer $V$. The prevalence of personality disorders in a community sample. Arch Gen Psychiatry. 2001;58:590-6.

7. Widiger TA. A shaky future for personality disorders. Personal Disord. 2011;2:54-7.

8. American Psychiatric Association. Diagnostic and Statistical Manual of Mental Disorders 5. Washington: APA; 2013.

9. Krueger RF, Derringer J, Markon KE, Watson $D$, Skodol AE. Initial construction of a maladaptive personality trait model and inventory for DSM-5. Psychol Med. 2011;8:1-12.

10. Carvalho LF, Primi R. Manual técnico do Inventário Dimensional Clínico da Personalidade-2 (IDCP-2) e versão triagem. São Paulo: Pearson. Forthcoming 2018.
11. American Psychiatric Association. Diagnostic and Statistical Manual of Mental Disorders. 4th ed Revised. Washington: APA; 2003.

12. Millon T, Davis RD. Disorders of personality: DSM-IV and beyond. New Jersey: Wiley; 1996

13. Millon T, Grossman S. Moderating severe personality disorders. New Jersey: John Wiley \& Sons; 2007.

14. Millon T, Grossman S. Overcoming resistant personality disorders. New Jersey: John Wiley \& Sons Inc; 2007.

15. Millon T, Grossman S, Tringone R. The Millon Personality Spectrometer: a tool for personality spectrum analyses, diagnoses, and treatments. In: Millon $\mathrm{T}$, editor. Disorders of Personality: introducing a DSM/ICD spectrum from normal to abnormal. New Jersey: Wiley; 2010. p. 391-416.

16. Carvalho LF, Primi R. Development and internal structure investigation of the Dimensional Clinical Personality Inventory (IDCP). Psicol Reflex Crit. 2015;28:322-30.

17. Carvalho LF, Primi R, Stone GE. Psychometric properties of the Dimensional Clinical Personality Inventory (IDCP) using the Rating Scale Model. Av Piscol Clin Latinonot. 2014;32:433-46.

18. Abela RK, Carvalho LDF, Cho SJM, Yazigi L. Validity evidences for the Dimensional Clinical Personality Inventory in outpatient psychiatric sample. Paideia (Ribeirão Preto). 2015;25:221-8.

19. Carvalho LF, Sette CP. Revision of the criticism avoidance dimension of the Dimensional Clinical Personality Inventory. Estud Psicol (Campinas). 2017;34:219-31.

20. Millon T. Disorders of personality: Introducing a DSM/ICD spectrum from normal to abnormal. 3th ed. New Jersey: Wiley; 2011.

21. Westen D, Shedler J. Revising and assessing Axis II, part I: developing a clinically and empirically valid assessment method. Am J Psychiatry. 1999;156:258-72.

22. Clark LA. Toward a consensual set of symptom clusters for assessment of personality disorder. In: Butcher JN, Spielberger $C D$, editors. Advances in personality assessment. New Jersey: Lawrence Erlbaum Associates; 1990.

23. Carvalho LF, Arruda W. Revisão da dimensão isolamento do Inventário Dimensional Clínico da Personalidade. Temas Psicol. 2016;24:47-61.

24. Carvalho LF, Pianowski G. Revision of the dependency dimension of the Dimensional Clinical Personality Inventory. Paideia (Ribeirão Preto). 2015;25:57-65.

25. Carvalho LF, Pianowski G, Miguel FK. Revision of the aggressiveness dimension of Dimensional Clinical Personality Inventory. Psicol Teor Prat. 2015;17:146-63.

26. Carvalho LF, Sette CP, Capitão CG, Primi R. Propriedades psicométricas da versão revisada da dimensão necessidade de atenção do Inventário Dimensional Clínico da Personalidade. Temas Psicol. 2014;22:147-60.

27. Carvalho LF, Silva GC. Review of the self-sacrifice dimension of the Clinical Dimensional Personality Inventory. Psicol Reflex Crit. 2016;29:2-6.

28. Wolfe EW. Equating and item banking with the Rasch model. J Appl Meas. 2000;1:409-34.

29. Wright BD, Masters GN. Rating scale analysis. Chicago: MESA; 1982.

30. Linacre JM. Winsteps $®$ version 3.72.3 [computer software]. Beaverton: Winsteps.com; 2011.

31. Wright BD, Linacre JM. Reasonable mean-square fit values. Rasch Meas Trans. 1994;8:370.

32. Daniel MH. Behind the scenes: using new measurement methods on the DAS and KAIT. In: Embretson SE, Hershberger SL, editors. The new rules of measurement: What every psychologist and educator should know. New Jersey: Lawrence Erlbaum; 1999. p. 37-63.

33. Elliot R, Fox CM, Beltyukova SA, Stone GE, Gunderson J, Zhang $X$. Deconstructing therapy outcome measurement with Rasch analysis of a measure of general clinical distress: The SCL-90-R. Psychol Assess. 2006;18:359-72.

34. Linacre JM. Winsteps Rasch measurement computer program. Ilinois: Winsteps; 2009.

35. Thissen D. Reliability and measurement precision. In: Wainer $H$, editor. Computerized adaptive testing: A primer. 2nd ed. New Jersey: Lawrence Erlbaum; 2000. p. 159-84.

36. Skodol AE, Clark LA, Bender DS, Krueger RF, Morey LC, Verheu $R$, et al. Proposed changes in personality and personality disorder assessment and diagnosis for DSM-5 part I: description and rationale. Personal Disord. 2011;2:4-22.

37. Braga ACS. Curvas ROC: aspectos funcionais e aplicações [dissertation]. Braga: Universidade do Minho; 2000. 
38. Andreoli SB, Blay SL, Mari JJ. Escalas de rastreamento de psicopatologia. Psiquiatr Clin. 1998;25:229-32.

39. Fletcher $\mathrm{RH}$, Fletcher SW, Wagner EH. Epidemiologia clínica: elementos essenciais. Porto Alegre: Artmed; 1996.

40. Carvalho LF, Primi R, Meyer GJ. Application of the Rasch model in measuring personality disorders. Trends Psychiatry Psychother. 2012;34:101-9.

\section{Correspondence:}

Lucas de Francisco Carvalho

Universidade São Francisco

Rua Alexandre Rodrigues Barbosa, 45

13251-900 - Itatiba, SP - Brazil

Tel. : +55 (11) 45348053

E-mail: lucas@labape.com.br 